\title{
К ПРОБЛЕМЕ СОХРАНЕНИЯ КУЛЬТУРНОГО НАСЛЕДИЯ НАРОДОВ РЕСПУБЛИКИ АЛТАЙ
}

\section{ON THE PROBLEM OF PRESERVING THE CULTURAL HERITAGE OF THE PEOPLES OF THE ALTAI REPUBLIC}

\section{E. Enchinov}

Summary: The article examines the cultural heritage of the peoples of the Altai Republic. Altaians, russians, telengits, tubalars, kumandins, chelkans and kazakhs have been living in the region under study for a long time and in good-neighborly relations. The existing elements of traditional material culture (clothing, food, and housing).

Keywords: Altai Republic, altai, russians, kazakhs, indigenous peoples, culture, ethnography, traditions, custom.
Енчинов Эркин Валериевич

К.и.н., С.н.С., БНУ Республики Алтай

«Научно-исследовательский институт алтаистики им. С.С. Суразакова», г. Горно-Алтайск

enchinov_e@mail.ru

Аннотация: В статье рассматривается культурное наследие народов Республики Алтай. В исследуемом регионе длительное время и в добрососедских отношениях проживают алтайцы, русские, теленгиты, тубалары, кумандинцы, челканцы и казахи. Кратко описываются бытующие элементы традиционной материальной культуры одежда, пища, жилище.

Ключевые слова: Республика Алтай, алтайцы, русские, казахи, коренные малочисленные народы, культура, этнография, традиции, обычай.
$P$ еспублика Алтай - субъект Российской Федерации, расположен в южной части Западной Сибири и входит в Сибирский федеральный округ, занимает 35-е место по площади территории (92 903 тыс. кв. км.) и 81-е место по численности населения (221050 чел.) среди субъектов по состоянию на 1 января 2021 г., плотность населения - 2.38 чел./кв. км. [7].

Национальный состав региона согласно данным переписи 2010 г. представлен 91 национальностью [2]. Мозаика этнических групп представлена русскими 55,68 \%, алтайцами 35,33 \%, казахами 6,07 \% и 2,92 \% другие этнические группы [4].

В данной статье мы остановимся только на ряде народов, проживающих в исследуемом регионе, это алтайцы, русские, казахи и коренные малочисленные народы Республики Алтай: теленгиты, тубалары, кумандинцы и челканцы. Указанные народы имеют длительную историю совместного проживания, многочисленные межнациональные браки, билингвизм и трилингвизм в семьях, совместное использование пастбищ, охотничьих и сенокосных угодий, таежных массивов при сборе дикоросов, в т.ч. и в промышленных масштабах. Широкое хождение в культуре питания жителей региона имеют такие блюда как щи, борщ, бешбармак, јёргём, кан и кёчё. При этом хотим отметить, что ни в коей мере не хотим умалить достоинства и уникальность культуры других народов, проживающих в добрососедстве и взаимном уважении в исследуемом регионе вот уже не одно десятилетие.

В Республике Алтай, как и по всей стране в 90-х гг. XX в. активно обсуждались вопросы этнической идентич- ности и культурного возрождения, также нужно учесть, что исследуемый регион, традиционно национальный. В указанное время произошли политические и юридические трансформации, это достижение статуса республики, формирование органов власти, принятие конституции Республики Алтай, также таких атрибутов как флаг, герб, гимн. В указанное время в регионе произошли значительные трансформации, как в культурно-религиозной сфере, так и в ее материальной составляющей, изменилось сознание граждан, выразившееся в новой этнической идентификации субэтносов, некогда входивших в единый состав алтайского народа. Теленгиты, тубалары, челканцы в 2000 г. были отнесены к коренным малочисленным народам Российской Федерации (Постановление Правительства Российской Федерации № 255 от 24.03.2000 г.) [5]. Еще ранее в начале 1990-х гг. кумандинцы были отнесены к малочисленным народам (Постановлением Совета национальностей Верховного Совета Российской Федерации за №4538-1 от 24.02.1993 г.) [6]. Всероссийская перепись населения 2002 г. учла их отдельными народностями со своим языком, но во Всероссийской переписи 2010 г. представителей этнических групп теленгитов, тубаларов, кумандинцев и челканцев учли уже субэтносами в составе алтайцев.

Многообразие национального этнического состава, межкультурное и межрелигиозное взаимодействие служат факторами укрепления российской государственности, что гарантируется основным документом страны Конституцией Российской Федерации и подкрепляется рядом краеугольных документов, в том числе «Стратегией государственной национальной политики Российской Федерации на период до 2025 года» [10]. 
Столпы традиционной материальной культуры как одежда, пища, жилище, в 90-е гг. XX в. во многих уголках страны стали яркими маркерами выражения этнической самоидентификации. Но за прошедшие четверть века этнографическая триада также подверглась анализу и переосмыслению, в первую очередь, среди носителей культуры. Если в конце XX в. традиционные жилища или одежда служили своего рода демонстрацией и «провозглашением» собственной этничности, то к началу третьего десятилетия людям стало важно понимание того, как в целом работает материальный предмет в традиции, стали важны воспитательные функции одежды, пищи и жилища.

Традиционная одежда жителей Горного Алтая, как и раньше, соответствует различным бытовым ситуациям, поэтому подразделяется на повседневную и праздничную, в зависимости от климатических условий на зимнюю и летнюю, от возраста её обладателя на одежду детей и подростков, молодежи, взрослых и пожилых людей, а от пола на мужскую и женскую [9; 1].

В алтайской культуре на начало XXI В. хорошую сохранность демонстрирует верхняя плечевая одежда мужчин и женщин - шуба тон, которую шьют из овечьих шкур. Из легкой верхней одежды бытуют разные по компоновке безрукавки, которые носят как в повседневной жизни, так и на праздниках. К категории легкой верхней женской одежды относиться чегедек - длиннополая безрукавка, надевающейся поверх свадебного платья девушки во время свадебной церемонии, имеющей символическое значение, отражающее переход девушки в статус замужней женщины [9; 3].

Традиционная русская одежда мужчин, бытовавшая в регионе, отличалась простотой покроя. Мужские рубахи были следующих типов: туникообразные, на кокетке и с плечевыми швами. Мужчины всегда носили рубаху навыпуск, прикрывая портки. Из женской одежды, в исследуемом регионе, самой архаичной считается рубаха/ сорочка туникообразного кроя. Верхнюю часть туникообразной рубахи изготавливали из льняной или конопляной, хлопчатобумажной или шёлковой ткани. Нижнюю часть шили из плотного домотканого холста. Центральное полотнище такой рубахи перегибалось пополам, образуя перед и спинку. На сгибе прорезалось отверстие и разрез ворота. В настоящее время такие костюмы можно встретить на общественных и семейных праздниках русского населения.

Казахи традиционную одежду изготавливали из меха, кожи и ткани. Казахи Кош-Агачского района в холодное время продолжают носить традиционную теплую шубу тон из обработанной овечьей шкуры. Шубу из овчины шьют мехом внутрь. Ворот и рукава оторачивают мехом пушных зверей. Женское одеяние состоит из несколь- ких частей. Чаще всего, это камзол и платья - косэтек. В теплое время года носят легкий чапан, а в холодное - с шерстяной подкладкой, которая простегивается вместе с верхом.

Основу традиционную питания народов исследуемого региона составляла мясная, молочная и растительная пища, чему способствовал ландшафт, история, традиции, этногенетические связи сформировавшие пищевые модели, тесно связанные с хозяйственно-культурными типами.

В употребление идут различные блюда из мяса таких домашних животных как лошадь, крупный и мелко рогатый скот, як, верблюд, диких зверей - косули, марала, дикого козла, барсука, медведя и др.

Из супов население Республики Алтай, часто готовят щи, борщ, рассольник, солянку, окрошку. Например, щи - это одно из самых употребляемых блюд современной русской семьи в регионе. Готовят щи из свежей или квашеной капусты, щавеля. Одним из любимых супов остается борщ, это одновременно и праздничное, и повседневное блюда.

В меню коренных жителей региона в начале XXI в. как и ранее большое место продолжают занимать продукты, изготовленные из производных молока, как например сквашенное молоко чеген, также собственно свежее коровье молоко, в теплое время года на селе можно отведать настоящий деликатес кобылье молоко кымыс. Традиционный алтайский чай с солью, обрушенными зернами жаренного ячменя талкан и домашним маслом сарју в обязательном порядке белиться свежим коровьим молоком.

На протяжении длительного времени народы региона сформировали свои особые типы и формы поселений и жилищ максимально адаптированных к местной природно-климатической среде и формам ведения хозяйства. К числу традиционных жилищ коренных жителей Горного Алтая относятся постоянные, сезонные и временные, стационарные и переносные, разной конструкции: конческой, пирамидообразное каркасное жилище, прямоугольное четырехстенное из жердей и коры с конической крышей, решетчатое цилиндрическое и многоуголные срубы с конической корьевой крышей [8, с. 120]. Традиционные жилища имеющие бытование в алтайской культуре и на начало XXI в. это такие типы, как: конический, цилиндрический (решетчатая) айылы, многоугольный сруб и дощатый летник.

Поселения русского населения в Республике Алтай размещались вдоль водоемов, ручьев и вблизи лесных массивов, что было обусловлено хозяйственной деятельностью. 
В настоящее время сохранившимися типами традиционных жилищ русского населения Республики Алтай можно назвать срубную однокамерную избу, двухкамерный пятистенный дом и трёхкамерный или трехчастный домом - изба-связь (дом-связь).

Дома традиционно строили из пихты, лиственницы иногда из кедра; хозяйственные постройки - из сосны, лиственницы. При этом надо отметить, из-за современных процессов глобализации происходит исчезновение, изменение самобытных черт материальных и духовных маркеров. Но веками проверенная конструкция традиционной русской избы не претерпевала сильных изменений. Например, у самого распространенного типа жилища русского населения региона у дома пятистенка сруб имеет прямоугольную форму, разделен поперечной стеной на две камеры: «избу» и «горницу». Капитальная пятая стена внутри избы укрепляет и связывает основу сруба, несет дополнительную нагрузку, поддерживая вес верхних конструкций. Такой тип дома мог быть значительно больших размеров, поэтому изба пятистенок была широко распространена по всей территории Сибири [11].

Казахи на территории Горного Алтая расселились в конце XIX в., занимались экстенсивным кочевым и полукочевым скотоводством, что предопределило их тип жилища - решетчатую юрту. В настоящее время традиционная юрта продолжает использоваться как летнее жилье, особенно животноводами на дальних стоянках.

Стены юрты состоят из решетчатых звеньев, связанных между собой тканой тесьмой, верхнего обода и жердями служащих скатом крыши, войлочный покров юрты состоит из четырех основных частей, соответствующих четырем частям каркаса.

В начале XXI в. жилища, в том числе и традиционные переходят в новую социально-экономическую категорию, они уже являются не только местом обитания членов семьи, но обретают такие характеристики как маркер успешности, престижности. Традиционные жилища, служа летниками, кухнями в теплое время года, в условиях районных центров и города также становятся способом самоидентификации хозяина, выражением его этнической идентичности.

Таким образом на начало 20-х гг. XXI в. перед научным сообществом исследуемого региона, в деле сохранения и развития культурного наследия народов Республики Алтай, формирования и укрепления общероссийской идентичности, крайне важным является решения следующих задач:

- проследить динамику этнокультурного развития коренных жителей, русского населения и казахов Республики Алтай;

- описать и дать анализ элементам традиционной материальной культуры исследуемых народов;

- определить роль и значение традиций хозяйствования в современной системе жизнеобеспечения;

- описать и подвергнуть анализу бытующие свадебные традиции исследуемых народов;

- проанализировать систему традиционной календарной обрядности;

- исследовать народные праздники, игры и эстрадное, фольклорное творчество самодеятельных коллективов, музыкальных групп;

- определить роль религиозных воззрений коренных жителей в современной культурной практике.

\section{ЛИТЕРАТУРА}

1. Алтайцы: Этническая история и традиционная культура. Современное развитие /НИИ Алтаистики им. С.С. Суразакова; редколл. Н.В. Екеев (отв. ред.). Н.М. Екеева, Э.В. Енчинов; НИИ алтаистики им. С.С. Суразакова. - Горно-Алтайск: Изд-во «ИП Пермяков С.А.», 2014. - 464 с.

2. Всероссийская перепись населения 2010 г. [Электронный ресурс]. Режим доступа: http://www.gks.ru/free_doc/new_site/perepis2010/croc/Documents/ Vol4/pub-04-04.pdf (дата обращения: 13.04.2021).

3. Кыдыева В.Я. Чегедек - эпши кижинин кеби. (Чегедек - одежда замужней женщины). - Горно-Алтайск: Изд-во АУ РА Литературно-издательский дом «Алтын-Туу», 2010. - 20 с.: илл. (на алт. яз.).

4. Население Республики Алтай (Системно-структурный анализ). [Электронный ресурс]. Режим доступа: http://e-lib.gasu.ru/eposobia/makoshev/ (дата обращения 10.04.2021).

5. Постановление Правительства РФ от 24 марта 2000 г. N 255 «0 Едином перечне коренных малочисленных народов Российской Федерации» (с изменениями и дополнениями). [Электронный ресурс]. Режим доступа: http://base.garant.ru/181870/\#ixzz6mu9Zусуі (дата обращения: 18.12.2020).

6. Постановлением Совета национальностей Верховного Совета Российской Федерации за №4538-1 от 24.02.1993 г. [Электронный ресурс]. Режим доступа: http://ivo.garant.ru/\#/doclist/13207:1 (дата 0бращения: 25.06.2020).

7. Республика Алтай. [Электронный ресурс]. Режим доступа: https://ru.wikipedia.org/wiki/\%D0\%A0\%D0\%B5\%D1\%81\%D0\%BF\%D1\%83\%D0\%B1\%D0\%BB\%D 0\%B8\%D0\%BA\%D0\%B0_\%D0\%90\%D0\%BB\%D1\%82\%D0\%B0\%D0\%B9\#DD0\%9D\%D0\%B0\%D1\%81\%D0\%B5\%D0\%BB\%D0\%B5\%D0\%BD\%D0\%B8\%D0\%B5 (дата обращения 24.02.2021).

8. Соколова 3.П. Жилище народов Сибири (опыт типологии). - М.: Изд-во ИПА «Три Л», 1998. - 288 с. 
9. Тюркские народы Сибири / отв. ред. Д.А. Функ, Н.А. Томилов; Ин-т этнологии и антропологии им. Н.Н. Миклухо-Маклая; Омский филиал Института археологии и этнографии СО РАН. - М.: Изд-во «Наука». 2006. - 678 с.

10. Указ Президента РФ от 19 декабря 2012 г. N 1666 «0 Стратегии государственной национальной политики Российской Федерации на период до 2025 года». [Электронный ресурс]. Режим доступа: http://base.garant.ru/70284810/\#ixzz4PxTys5pF (дата обращения: 13.11.2020).

11. Щеглова Т.К. Типы крестьянской архитектуры. [Электронный ресурс]. Режим доступа: https://www.altspu.ru/p_arh/russian/pamjatn/type.html (дата oбращения: 17.03.2021).

(c) Енчинов Эркин Валериевич (enchinov_e@mail.ru).

Журнал «Современная наука: актуальные проблемы теории и практики»

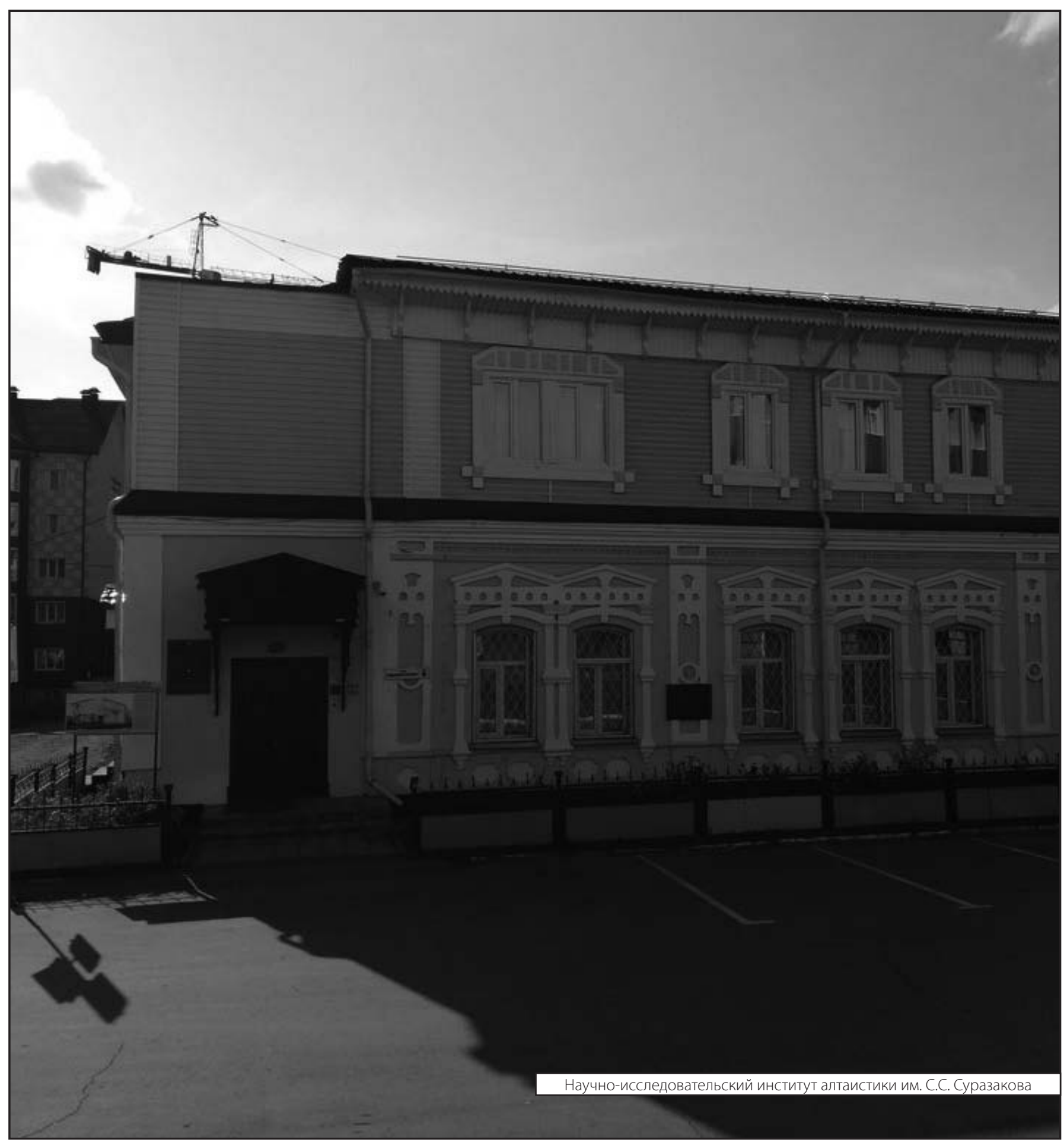

